\title{
Bell Labs bottoms out
}

It generated six Nobel prizes in as many decades, but after a string of staff departures, physicists claim that the once iconic Bell Laboratories has finally pulled out of basic science.

Just four scientists are left working in Bell's fundamental physics department in Murray Hill, New Jersey, Nature has learned. Others have either left or been reassigned to other parts of the company, and a major materials-fabrication facility has been shut down.

"Four people can't be called a basic research group," says Ronen Rapaport, who left the laboratory last summer for a position at the Hebrew University of Jerusalem. "It's a single project."

But officials at Alcatel-Lucent, Bell's parent company, say that reports of the lab's death are greatly exaggerated. Fundamen-

tal science remains, but it has moved away from physics, says Gee Rittenhouse, vice-president of research at Bell Labs. "We've shifted the fundamental research over to include mathematics, computer science, networking and wireless," he says.

Founded in 1925, Bell Labs was once considered the world's pre-eminent industrial laboratory for physics (see 'Moving with the times'). Scientists working there regularly won Nobel prizes, including ones for the

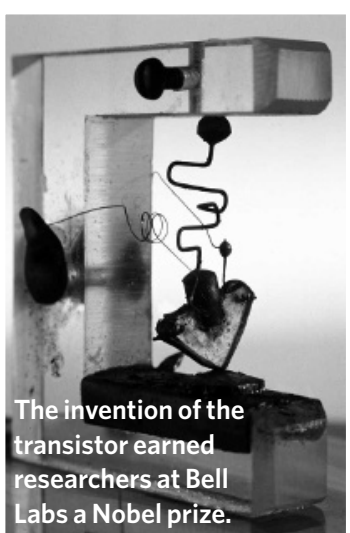

The latest troubles of the parent company have been mirrored at the lab. Alcatel-Lucent does not provide information about redundancies, but Bell's Murray Hill campus has been "heavily consolidated" since the merger, according to Bettina Tratz-Ryan, a telecoms analyst with Gartner, an IT market-research firm based in Stamford, Connecticut. Stafflevels have been cut and some buildings have been sold to property speculators. In February, Bell shut down a topof-the-line silicon fabrication facility once used by materials scientists. Rittenhouse confirmed that around 20 people were made redundant or reassigned as a result of the shutdown.

Given the grim outlook, many scientists started to look for other work to avoid redundancy, according to Vladimir Aksyuk, a visiting professor at the US National Institute of Standards and Technology in Gaithersburg, Maryland, who left Bell Labs in May. Throughout the turmoil, a small and talented group of roughly 30 physicists remained committed to basic research, but most have now left for more stable jobs. "The company just can't support research anymore," Aksyuk says. "Walk down the halls and there's a bunch of empty rooms."

"Almost everyone has gone invention of the transistor and the laser. Much of the early work was funded by the enormous profits of Bell's then parent company, AT\&T, which held a monopoly on US telecommunications for more than half a century. But deregulation forced AT\&T to split off Bell and other parts of the company into Lucent Technologies in 1996. Lucent struggled to finance its new research arm and the situation rapidly deteriorated after demand for telecommunications equipment collapsed in 2001.

Faced with redundancies and cutbacks, the lab's reputation was dealt a further blow in 2002, when one of its star researchers, Jan Hendrik Schön, was found to have falsified data in more than a dozen papers (see Nature 419, 419-421; 2002). Some believed that the lab's fortunes could be reversed by Lucent's merger with French telecom firm Alcatel in 2006 (see Nature 440, 1111; 2006). But Alcatel-Lucent has faced six consecutive quarterly losses and its stock value has halved since the merger. On 29 July, Serge Tchuruk, the company's chairman, and Patricia Russo, its chief executive, both announced that they would step down. away now," agrees Dick Slusher, a former Bell researcher now at the Georgia Institute of Technology in Atlanta. Slusher and others say that just Mike Manfra, Lauren Pfeiffer, Steve Simon and Robert Willett continue to conduct basic physics research at the laboratory.

Rittenhouse does not deny that the lab's focus has changed, but says Bell's research needs to be aligned with the company's needs. Lucent spunoff its semiconductor business in 2002 and its business needs have since moved away from materials science and towards networking, he says. "We've had to adjust our physics group's focus." In addition to quantum computing, he says, Alcatel-Lucent's 850 or so researchers continue to work on high-speed electronics and micromechanical electronic devices. "We can still do good research," he argues.

For physicists such as Rapaport, however, the halcyon days are over. The stock certificates he brought with him from Alcatel-Lucent are so diminished in value that he won't even bother to sell them, he says. Instead, "I can hang them on the wall as a memory of Bell Labs."

Geoff Brumfiel

\section{Moving with the times}

1925 Bell Labs founded as a merger between the Western Electric Company and AT\&T.

1927 Clinton Davisson demonstrates electron diffraction.

1947 John Bardeen, Walter Brattain and William Shockley (below) invent the transistor.

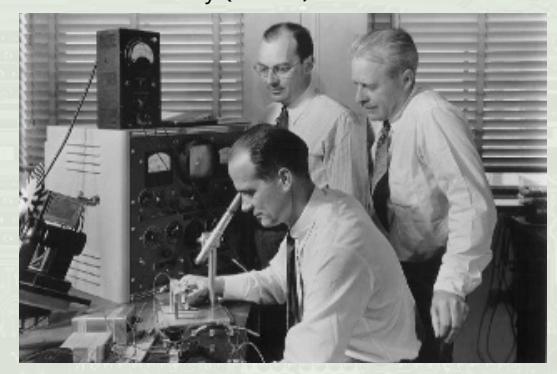

1958 Arthur Schawlow and Charles Townes describe the concept of the laser.

1962 Bell Labs builds Telstar I (below), the first orbiting communications satellite.

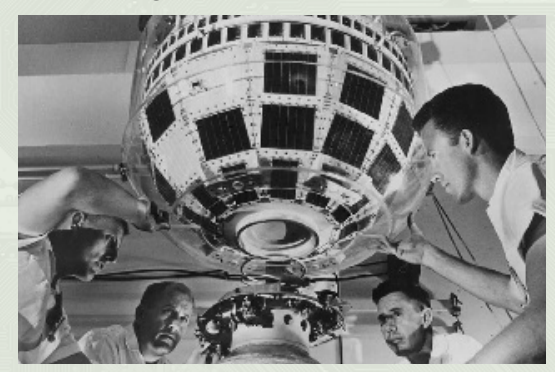

1965 Arno Penzias and Bob Wilson identify cosmic background radiation leftover from the Big Bang using the Horn reflector antenna (below) in Holmdel, New Jersey.

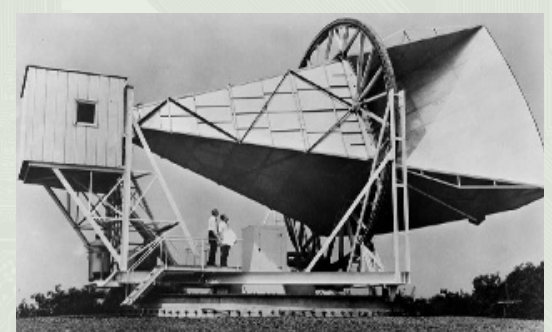

1969 Ken Thompson and Dennis Ritchie develop the UNIX operating system.

1982 Horst Stormer, Robert Laughlin and Daniel Tsui demonstrate the fractional quantum Hall effect.

1985 Steven Chu uses lasers to cool and trap atoms.

1996 Lov Grover develops quantum algorithm for speedy searches of unsorted databases. 